Antonio Gallarello ${ }^{1}$

Department of Electronics, Information and

Bioengineering (DEIB),

Politecnico di Milano,

Milano 20133, Italy

Andrea Palombi ${ }^{1}$

Department of Mechanical Engineering,

University College,

London WC1E 7JE, UK

Giacomo Annio ${ }^{1}$

Department of Mechanical Engineering,

University College,

London WC1E 7JE, UK

Shervanthi HomerVanniasinkam

Department of Mechanical Engineering, University College, London WC1E 7JE, UK; Leeds Vascular Institute, Leeds General Infirmary,

Leeds LS1 3EX,UK

Elena De Momi

Department of Electronics, Information and Bioengineering (DEIB),

Politecnico di Milano,

Milano 20133, Italy

Gabriele Maritati

Vascular and Endovascular Unit,

Perrino Hospital, ASL-Br,

Brindisi 72100, Italy

Ryo Torii

Department of Mechanical Engineering,

University College,

London WC1E 7JE, UK

Gaetano Burriesci

Department of Mechanical Engineering,

University College,

London WC1E 7JE, UK

Ri.MED Foundation,

Via Bandiera 11

Palermo 90133, Italy

Helge A. Wurdemann²

Department of Mechanical Engineering.

University College,

London WC1E 7JE, UK

e-mail: h.wurdemann@ucl.ac.uk

\title{
Patient-Specific Aortic Phantom With Tunable Compliance
}

Validation of computational models using in vitro phantoms is a nontrivial task, especially in the replication of the mechanical properties of the vessel walls, which varies with age and pathophysiological state. In this paper, we present a novel aortic phantom reconstructed from patient-specific data with variable wall compliance that can be tuned without recreating the phantom. The three-dimensional (3D) geometry of an aortic arch was retrieved from a computed tomography angiography scan. A rubber-like silicone phantom was manufactured and connected to a compliance chamber in order to tune its compliance. A lumped resistance was also coupled with the system. The compliance of the aortic arch model was validated using the Young's modulus and characterized further with respect to clinically relevant indicators. The silicone model demonstrates that compliance can be finely tuned with this system under pulsatile flow conditions. The phantom replicated values of compliance in the physiological range. Both, the pressure curves and the asymmetrical behavior of the expansion, are in agreement with the literature. This novel design approach allows obtaining for the first time a phantom with tunable compliance. Vascular phantoms designed and developed with the methodology proposed in this paper have high potential to be used in diverse conditions. Applications include training of physicians, pre-operative trials for complex interventions, testing of medical devices for cardiovascular diseases (CVDs), and comparative Magnetic-resonance-imaging (MRI)-based computational studies. [DOI: 10.1115/1.4044611]

Keywords: applied mechanics, cardiovascular diagnostics, clinical applications, tissue engineering

\section{Introduction}

Cardiovascular disease (CVD) has evolved into a worldwide epidemic and is the leading cause of death globally [1,2]. In the European region, CVDs account for $45 \%$ of all fatalities with

\footnotetext{
${ }^{1}$ A. Gallarello, A. Palombi, and G. Annio equally contributed to this manuscript.

${ }^{2}$ Corresponding author.

Manuscript received March 31, 2019; final manuscript received August 9, 2019; published online October 11, 2019. Assoc. Editor: Vanessa Diaz-Zuccarini.
}

$3.9 \times 10^{6}$ of deceases each year [2]; there were just under $11.3 \times 10^{6}$ new cases in 2015 with more than $85 \times 10^{6}$ people living with CVDs [2]. Increasing occurrence of CVDs at advanced age requires costly surgical operations to be conducted in a minimal invasive way [2,3]. Considering a decrease in mortality rate and a higher life expectancy in many middle and high-income countries [3], the cardiovascular devices market with a value of $\$ 33$ billion in 2015 is projected to grow at a compound annual rate of $6.6 \%$. Its expansion is mainly triggered by the need for 
new devices capable of reducing hospitalization costs, patients' pain and recovery time [4]. As CVDs do not only represent a health issue but also a major economic burden managing on how to control symptoms and conditions, their total global cost is set to rise from approximately USD $\$ 863$ billion in 2010 to a staggering USD $\$ 1,044$ billion in 2030 [5]. Early diagnosis and minimal invasive interventions could play a significant role in this framework.

Imaging techniques such as magnetic resonance imaging play a major role in early diagnosis of CVDs. Fluid-dynamic-relevant biomarkers have been investigated to assess initiation and development of CVDs such as atherosclerosis and aneurysms [6]. However, spatial and temporal resolutions and artifacts still constitute obstacles because they are strongly related to the time of scanning and to patient movement. Well-established tools in engineering are also image-based computational methods such as computational fluid dynamics and fluid-structure interaction. These computational approaches could give invaluable insights into cardiovascular medicine by allowing the modeling of healthy and pathological conditions, the enhancement of diagnostic assessment and the prediction of the outcomes of device implantations or interventions [7-9]. Nevertheless, further investigations are required to validate these approaches $[10,11]$.

Increasingly high level of surgical skills and experience is required to successfully perform cardiovascular interventions, due to the growing variety of medical devices to treat CVD, the intrinsic complexity of interventions, and the lack of sufficient training and adequate surgical planning. In particular, in minimally invasive interventions where the procedures are image guided, such as transcatheter aortic valve implantation [12,13], coronary stent implantation [14] or aortic endografting [15,16], relevant skills and experience are of paramount importance. In these cases, the anatomical complexity, malpositioning, or migration of prosthetic devices affects the outcome of the treatment and may lead to the conversion to invasive surgery $[17,18]$. Here, patient-specific phantoms offer great potential to overcome some of the aforementioned challenges as they allow longer scanning times (resulting in higher resolution), absence of patient motion and the assessment of the cardiovascular parameters after device implantations [19]. Phantoms could further constitute an optimal validation tool for computational approaches [20]. Also, in vitro tests ensure controllable and repeatable experimental conditions in a cost- and time-efficient way [21].

Researchers have investigated rigid [22] as well as flexible models [23]: rigid phantoms were historically made of glass to allow transparency. Recently, advancements in additive manufacturing techniques - three-dimensional (3D) printing-have permitted rapid fabrication of cost-effective transparent prototypes of patient-specific geometries using rigid materials [20,24]. Though these phantoms are ideal for flow visualization studies, the absence of compliance of the vessel walls does not allow to closely mimic the physiological behavior of anatomical structures leading to inaccuracy of fluid dynamic quantities [25] and failing to reproduce conditions in which devices are deployed. These shortcomings limit their application in clinical training [22]. 3D printers such as the Objet500 Connex3 printer by Stratasys, Inc., (Rehovot, Israel) allow to build layers of compliant rubber-like materials such as TangoPlus [26]. However, this technique is still unsuitable for the modeling of large arteries, due to the inhomogeneities produced by the manufacturing process, which result in a fragile phantom, and the highly viscoelastic behavior of the material, which may result in bulges and ruptures when the prototype is subjected to cyclic loads [26].

Hence, for the phantom developed in this work, a casting technique with silicone material was preferred. Though this process requires an accurate selection of the polymeric material, mold geometries, and atmospheric conditions [27], once optimized allows to obtain a suitably uniform thickness of silicone (this is more challenging when employing dip casting approaches), in the range of the patient-specific vessel walls, and physiological compliances. The initial step of a molding technique involves 3D printing of several parts of the mold that can be aligned to a $3 \mathrm{D}$ negative of the final prototype. Then, polymeric material is poured into the mold, cured and then extracted. Here, an inner 3D printed prototype was coated layer by layer with silicone dispersion, and cured before each subsequent coating. The vessel compliance of the developed vascular phantoms using the dipping or molding approach depends on the material choice for the silicone dispersion, as well as on the curing process $[27,28]$.

In this work, we present the design process and characterization procedure of a vascular phantom that allows to vary the vessel wall compliance, determined with respect to clinically relevant mechanical properties (i.e., compliance analyses during nonpulsatile and pulsatile conditions). Using patient-specific Computed Tomography (CT) data provided by the Centro Cardiologico Monzino, Milan, Italy, the 3D geometry of the aorta was segmented and a silicone-material phantom manufactured. The phantom features were determined using computational modeling of the material and of the vessel compliance at different pressure conditions. The entire phantom is hosted inside a chamber filled with de-ionized water connected to a tunable compliance chamber. Vascular phantoms designed and developed with the proposed methodology have high potential to be used in diverse environments. Applications include training of physicians, preoperative trials for complex interventions, testing of medical devices for cardiovascular diseases, and comparative MRI-based computational studies.

\section{Materials and Methods}

The design process of this patient-specific aortic phantom was inspired by procedural steps found in Ref. [29]. The design process is summarized in the flowchart in Fig. 1. First, the aorta contained within the patient CT scan was segmented. Mechanical characterization of alternative polymers was performed by means of uniaxial mechanical testing, to determine the stress-strain curves for the different materials and identify the best fitting hyperelastic constitutive model. These were then validated numerically with numerical models replicating the loading and geometries of the tested specimens. Then, each material model was used to describe a vessel of idealized geometry, subjected to a range of pressures. The values estimated for the vessel compliance and the distensibility were used to select an appropriate material and thickness for the phantom. In Secs. 2.1-2.5, the design process is described in detail.

2.1 Image Segmentation. The original dataset was obtained from a CT-angiography of a 76-year-old patient who was undergoing a transcatheter aortic valve implantation procedure with relevant institutional ethical committee approval. The anonymized data provided in digital imaging and communications in medicine file format were obtained from the Centro Cardiologico Monzino, (Milan, Italy). The dataset comprises the entire thoracic aorta, the abdominal aorta and the femoral bifurcation. The patient had heavily calcified valve but there was no pathological condition (e.g., aneurysm and/or dissection) observed along the aorta.

The data were first imported to 3DSLICER, an open source software for digital imaging and communications in medicine file reading [30,31]. An image segmentation process was executed allowing to concentrate the segmentation efforts on a defined region of interest (RoI). The RoI for our aortic phantom included the ascending aorta, aortic arch, and descending thoracic aorta (Fig. 2). The vessel's lumen was extracted using a manual doublethreshold image segmentation method. The values of the threshold were adjusted to extract the entire lumen of the aorta. This resulted in unwanted anatomical structures with similar grayscale level in the image, such as the spine, being included in the output volume.

The selected anatomical structure was exported into stereolithography format and refined using computer aided design (CAD) software packages including GEOMAGIC CONTROL (3D System Inc., 


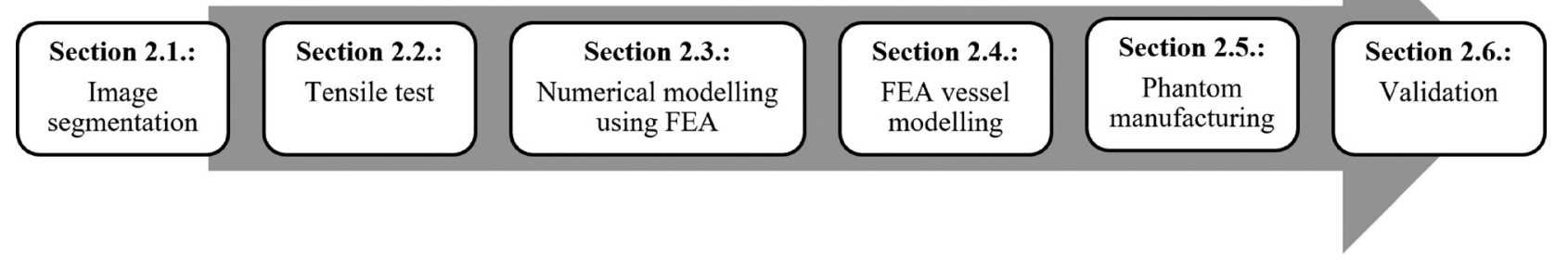

Fig. 1 Flowchart of the design process: In the initial step, the aorta was segmented within the patient's CT scan. Following experimental characterization and numerical description of selected material, the phantom was created using silicone material. The final prototype was validated according to mechanical properties.

Geomagic solution, Rock Hill, SC), 3DS MAX DESIGN and MESHMIXER (AUTODESK, Inc., San Rafael, CA). At this stage, the 3D model was smoothened freed from noise and artifacts derived by the thresholding method.

2.2 Tensile Tests. Four materials were considered to manufacture the phantom [31]: TangoBlackPlus FLX 980 (Stratasys, Inc.), Eco-Flex 00-30, Eco-Flex 00-50, and Dragon Skin 30 (smooth-on). The material selection was driven by material choices for vascular phantoms found in Refs. [26,28], and [32]. TangoBlackPlus FLX 980 is a rubber-like material that can be 3D-printed by an Objet500 Connex3 printer by Stratasys, Inc. The silicone and rubber materials by smooth-on are composites relying on dipping [33] or casting [34] manufacturing techniques. Each material was characterized by means of uniaxial tensile test resulting in a descriptive stress-strain curve. According to international standard protocols [35], ten $1 \mathrm{~mm}$ thick specimens for each material were prepared (by molding or $3 \mathrm{D}$ printing) with the profile shown in Fig. 3. Tests were conducted applying a constant deformation rate of $20 \mathrm{~mm} / \mathrm{min}$. Data processing and analysis was performed using MATLAB. For each test, nominal stress and strain were computed following equations:

$$
\begin{gathered}
\sigma=\frac{F}{A_{0}} \\
\varepsilon=\frac{\left(l-l_{0}\right)}{l_{0}}
\end{gathered}
$$

In Eq. (1), $\sigma$ is the engineering stress and does not consider the decrease of the cross-sectional area during the loading phase. This value can be determined by dividing the applied load $F$ measured instantaneously by the load cell and the cross-sectional area of the specimen at rest $A_{0}$. The true deformation $\varepsilon$ is computed as the ratio between the elongation $\left(l-l_{0}\right)$ and the initial length $l_{0}$ of the specimen.

Results indicated an elongation at break of about $500 \%$ for all silicone materials and $120 \%$ for TangoBlackPlus. To remain
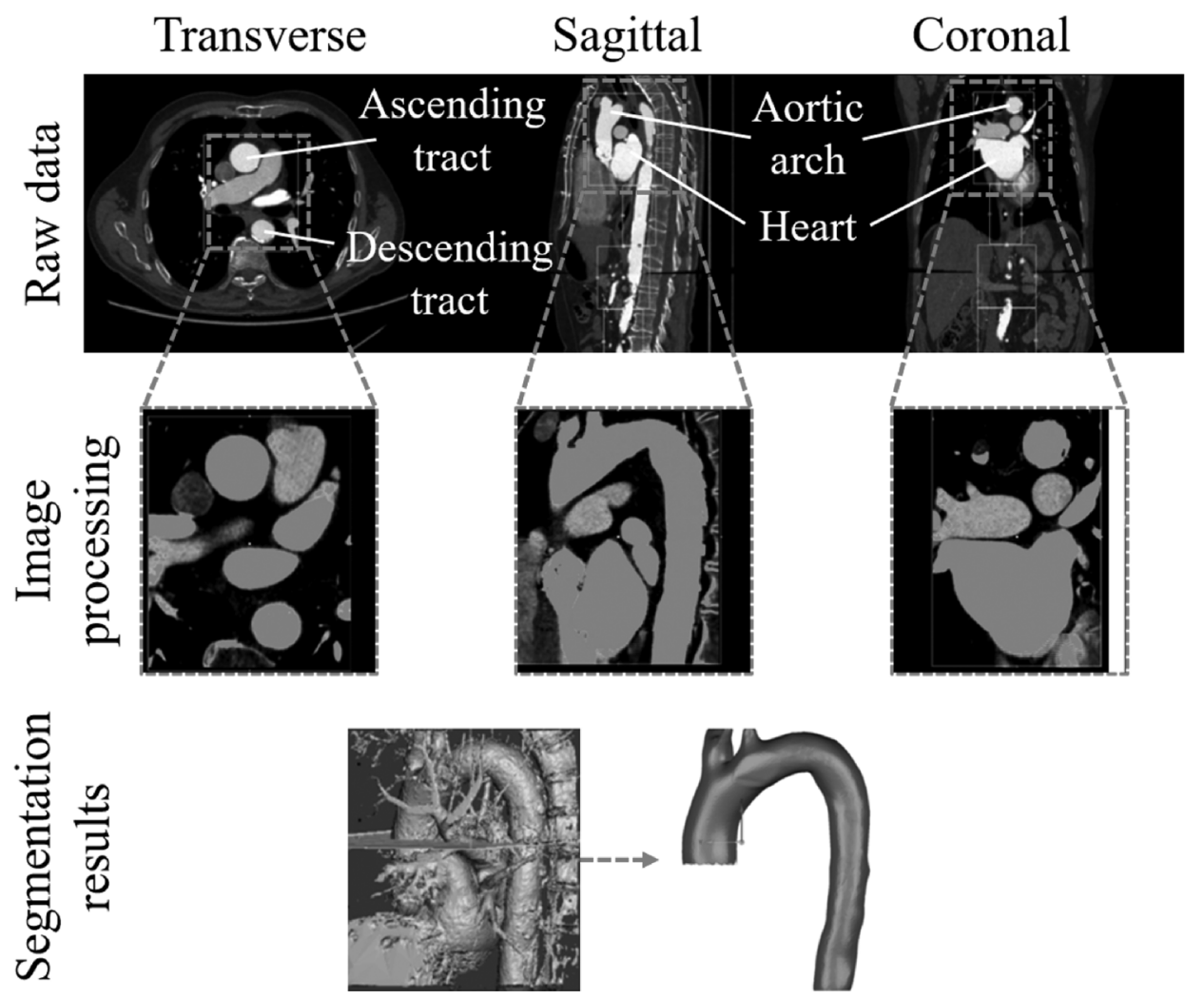

Fig. 2 Segmentation process leading to the extraction of a smooth lumen of the aorta: A double-threshold method was applied to the raw CT-data in 3Dslicer. The 3D reconstruction was then imported in Meshmixer and smoothened to finally obtain the final model of the aorta. 
within the elastic boundaries of the material and consider the maximum deformation of the human vessel tissue, results were obtained for up to $200 \%$ for the silicone materials and $100 \%$ for TangoBlackPlus.

2.3 Material Models in Finite Element Analysis. All materials were mathematically modeled to conduct a finite element analysis (FEA). A polynomial function was fitted to the uniaxial test data, obtaining plots shown in Fig. 4. The values of mean stress and the associated standard deviation are reported in Table 1.

The geometry and stress-strain curves of the aforementioned specimens (see Fig. 3) were imported into ABAQus CAE. A static step was defined to have a sufficient amount of samples describing the stress-strain response of the materials. Boundary conditions were defined to replicate the actual testing conditions: the bottom surface of the parallelepiped was fixed using the "Encastre" boundary condition to constrain translation and rotation along all axes. The top surface, on the other hand, was fixed avoiding any vertical movement. A displacement was applied to right-hand side using a ramp waveform. With no loss of generality, the part was meshed using a 20-node quadratic brick (C3D20RH Abaqus element type). A total of 20 simulations were carried out modeling the four materials with five different hyperelastic models: Ogden (first-, second-, and third-order), Neo-Hookean and reduced polynomial with second-order (for details see Appendix).

The results obtained for the constitutive models were compared with experimental stress-strain curves, computing the meansquared-error (MSE) and performing a paired $t$-test with a $5 \%$ significance level. The results are shown in Table 2. The constitutive model with a lower MSE highlighted in Table 2 and was selected to describe the specific material.

2.4 Finite Element Analysis Vessel Modeling. In order to assess the most suitable material to be used for the manufacturing of the phantom, FEAs provided a description of the compliance for all considered materials at different wall thicknesses under physiological pressures. The simulated geometrical model is a hollow tube with patient-specific dimensions retrieved from the CT scan pressurized at $100 \mathrm{mmHg}$. Two sets of simulation were performed:

(1) Inflated phantom with physiological blood pressure $(80-120 \mathrm{mmHg})$, surrounded by water at atmospheric pressure and

(2) Inflated phantom with physiological blood pressure $(80-120 \mathrm{mmHg})$, surrounded by water at static pressure of $100 \mathrm{mmHg}$.

The material properties of the vessel were defined according to Ref. [36] as graphically shown in Fig. 5. The boundary conditions were set to constrain any displacement and rotation along longitudinal and circumferential directions (see Fig. 6) because the simulated vessel wall is only a section of the entire vessel model. The model was then meshed using the C3D20RH Abaqus element type. A constant pressure equal to $100 \mathrm{mmHg}$ was applied to the outer surface, and the internal displacement computed.

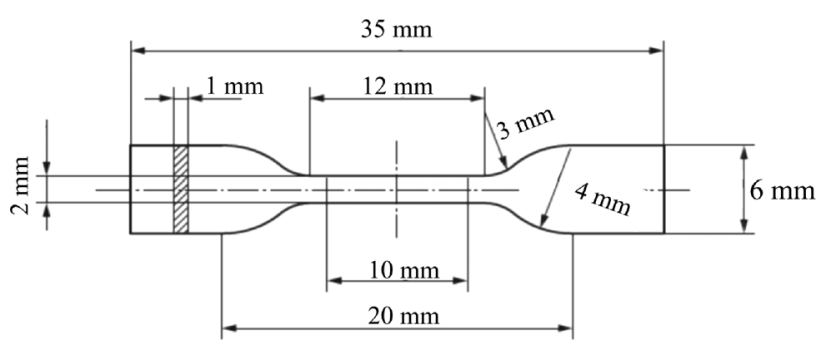

Fig. 3 Specimen geometry used for the tensile tests
Since the simulation model was obtained from the CT scan at a mean aortic pressure of about $100 \mathrm{mmHg}$, an equivalent model geometry at $0 \mathrm{mmHg}$ was created for these two sets of simulation. An idealized section of this vessel anatomy was generated in Abaqus $\mathrm{CAE}^{\circledR}$ with a simplified hollow tube model. In order to increase the resolution of the element, an axial-symmetric element was created by revolving a $20 \mathrm{deg}$ rectangular vessel section with an inflated radius of $13.38 \mathrm{~mm}$, inflated thickness of $2.4 \mathrm{~mm}$, radial displacement of $1.62 \mathrm{~mm}$ and deflated radius of $11.74 \mathrm{~mm}$ as shown in Fig. 6.

2.4.1 Simulation Under Atmospheric Pressure. Based on the virtual phantom model, the first simulation experiment involved applying a pressure of $80 \mathrm{mmHg}$ and $120 \mathrm{mmHg}$ when varying the thickness of the phantom wall. The displacement of the wall and the distensibility value were computed for these pressures for all four materials. The results are shown in Fig. 7.

The compliance curve of each material exponentially decreases with an increase in wall thickness. The shaded area in Fig. 7 visualizes the physiological range of the aortic vessel wall. TangoBlackPlus FLX 980, Eco-Flex 00-30, and Eco-Flex 00-50 achieve the distensibility within this interval. Further, the displacement of the inner wall of the hollow tube model was explored (Fig. 8). Starting from a deflated geometry, the model should behave like a vessel by reaching the same distensibility value. It is important to note that, on the other hand, this behavior is achieved with a mean radius similar to the original one. Hence, the internal radius at $80 \mathrm{mmHg}$ and $120 \mathrm{mmHg}$ was compared to the original dimensions of the CT scan (Fig. 8).

2.4.2 Simulation With Externally Applied Pressure. The second simulation experiment aimed at determining the most suitable material and wall thickness to be used in a condition where the phantom is inflated with physiological blood pressure $(120-80 \mathrm{mmHg})$ and surrounded by water and at a pressure of $100 \mathrm{mmHg}$ - approximating the condition where the aortic phantom is placed in a closed and sealed housing. For the FEA, our aforementioned hollow tube geometry was meshed using C3D20RH element type imposing boundary conditions equivalent to the ones applied in the first experiment. The model was then inflated with $80 \mathrm{mmHg}$ and $120 \mathrm{mmHg}$ maintaining a constant of $100 \mathrm{mmHg}$ pressure on the outer wall. The distensibility and displacement values are shown in Fig. 9.

2.4.3 Material Assessment. The results from the first set of simulations suggest that none of the examined materials would allow manufacturing an aortic phantom capable of achieving human-like distensibility without controlling the external pressure. In fact, for all material-thickness combinations, if external atmospheric pressure is considered, the physiological pressurization of the vessel results in large displacements, which lead to loss of the patient-specific dimensions. TangoBlackPlus seems to be most suitable material for low thickness value of the aortic wall. The drawback of this material is, however, that thin layers of printed TangoBlackPlus are extremely fragile when stretched.

The second simulations, on the other hand, advise that physiological dimensions can be maintained with the "inflated" vessel geometry. All materials can reproduce human-like distensibility values. TangoBlackPlus and Dragon Skin 30, however, achieve the required behavior only with very thin wall thicknesses, at which it is difficult to guarantee the adequate structural strength. Hence, Eco-Flex 00-30 was chosen, as physiological compliance values can be achieved with larger wall thickness values, similar to the human aorta. The overall thickness of the phantom was set to $2 \mathrm{~mm}$, which resembles the physiological dimension.

2.5 Phantom Design and Fabrication. The silicone aortic phantom was fabricated using a casting technique. This manufacturing process allows reproducing desired vessel wall thicknesses and geometries, which are either equivalent to the ones extracted 


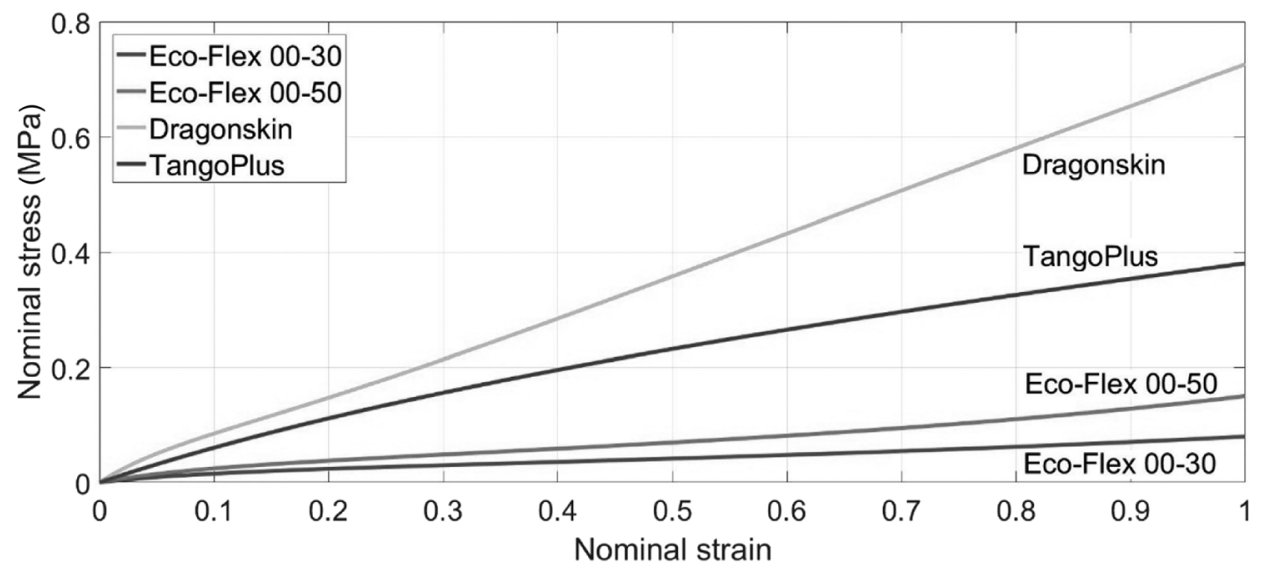

Fig. 4 Stress-strain curves to characterize TangoBlackPlus FLX 980, Eco-Flex 00-30, EcoFlex 00-50, and Dragon Skin 30

Table 1 Mean stresses and standard deviations for nominal strain values in the interval $[0.25, \ldots, 2]$

\begin{tabular}{|c|c|c|c|c|c|c|c|c|c|}
\hline \multicolumn{2}{|c|}{ Nominal strain value $( \pm 1 \%)$} & \multirow{2}{*}{$\begin{array}{c}0.25 \\
0.0154 \\
0.0021\end{array}$} & \multirow{2}{*}{$\begin{array}{c}0.50 \\
0.0248 \\
0.0032\end{array}$} & \multirow{2}{*}{$\begin{array}{r}0.75 \\
0.0320 \\
0.0040\end{array}$} & \multirow{2}{*}{$\begin{array}{c}1 \\
0.0385 \\
0.0052\end{array}$} & \multirow{2}{*}{$\begin{array}{c}1.25 \\
0.0461 \\
0.0057\end{array}$} & \multirow{2}{*}{$\begin{array}{c}1.5 \\
0.0545 \\
0.0068\end{array}$} & \multirow{2}{*}{$\begin{array}{c}1.75 \\
0.0655 \\
0.0082\end{array}$} & \multirow{2}{*}{$\begin{array}{c}2 \\
0.0772 \\
0.0095\end{array}$} \\
\hline Eco-Flex 00-30 & $\begin{array}{c}\bar{\sigma}(\mathrm{MPa}) \\
\text { Standard deviations }\end{array}$ & & & & & & & & \\
\hline Eco-Felx 00-50 & $\begin{array}{c}\bar{\sigma}(\mathrm{MPa}) \\
\text { Standard deviations }\end{array}$ & $\begin{array}{l}0.0238 \\
0.0021\end{array}$ & $\begin{array}{l}0.0387 \\
0.0028\end{array}$ & $\begin{array}{l}0.0510 \\
0.0032\end{array}$ & $\begin{array}{l}0.0640 \\
0.0043\end{array}$ & $\begin{array}{l}0.0799 \\
0 . .0050\end{array}$ & $\begin{array}{l}0.0993 \\
0.0070\end{array}$ & $\begin{array}{l}0.1218 \\
0.0089\end{array}$ & $\begin{array}{l}0.1459 \\
0.0102\end{array}$ \\
\hline Dragonskin & $\begin{array}{c}\bar{\sigma}(\mathrm{MPa}) \\
\text { Standard deviations }\end{array}$ & $\begin{array}{l}0.100 \\
0.0101\end{array}$ & $\begin{array}{l}0.1763 \\
0.0153\end{array}$ & $\begin{array}{l}0.02549 \\
0.0232\end{array}$ & $\begin{array}{l}0.3410 \\
0.0292\end{array}$ & $\begin{array}{l}0.4342 \\
0.0357\end{array}$ & $\begin{array}{l}0.5349 \\
0.0459\end{array}$ & $\begin{array}{l}0.6403 \\
0.0580\end{array}$ & $\begin{array}{l}0.7407 \\
0.0703\end{array}$ \\
\hline TangoPlus & $\begin{array}{c}\bar{\sigma}(\mathrm{MPa}) \\
\text { Standard deviations }\end{array}$ & $\begin{array}{l}0.1280 \\
0.0035\end{array}$ & $\begin{array}{l}0.2223 \\
0.0057\end{array}$ & $\begin{array}{l}0.3085 \\
0.0106\end{array}$ & $\begin{array}{l}0.3914 \\
0.0129\end{array}$ & - & - & - & - \\
\hline
\end{tabular}

from patient-specific imaging data or can be homogeneous across the entire aortic phantom.

An stereolithography file of the aorta (of a $22 \mathrm{~cm}$ height) obtained from the image segmentation procedure was imported into the CAD software packages SolidWorks and Geomagic to refine the mesh and build a second model, which represented the outer surface, i.e., the outer mold, of the 3D solid vessel (see Fig. 10). An offset value of $2 \mathrm{~mm}$ was applied to the 3D reconstructed geometry of the aorta, creating a free chamber between the inner and outer mold part for the silicone material. Centering pins and holes were modeled on the internal and external molds, respectively, to guarantee the correct alignment of the two main elements during the casting process. The outer mold was designed to be composed of multiple fitting parts. That highly simplifies the extraction process of the silicone aorta after the curing process. Each piece was 3D-printed with nylon using the Selective Laser
Sintering (SLS) technique (EOS Formiga P100). On the other hand, the inner core was printed with the poly vinyl alcohol (PVA), using a Delta Wasp Turbo 2040 FDM 3D printer. The soluble nature of PVA allows to easily dissolve the inner core in water avoiding the risk to damage the aortic phantom.

Figure 11 shows the resulting silicone aortic phantom embedded inside a housing filled with de-ionized water. To allow magnetic resonance (MR)-compatibility, the entire phantom consisted of nonferromagnetic materials. The housing was made of transparent acrylic material. Acrylic screws, gaskets, and sealing silicone were used to make the housing watertight. Constraints to the movement of the phantom were added at the inlet and outlet of the vessel, where rigid connectors were used to ensure the interface with external actuation systems, e.g., a pulse duplicator. A small Windkessel compliance chamber with a volume of $200 \mathrm{ml}$, designed according to Ref. [37], was connected to the phantom

Table 2 Mean-squared-error and $p$-values of the paired $t$-test between each constitutive model and the experimentally obtained stress-strain curve after interpolation

\begin{tabular}{|c|c|c|c|c|c|}
\hline Material & Ogden first & Ogden second & Ogden third & Red-Poly second & Neo-Hooke \\
\hline \multicolumn{6}{|c|}{ Constitutive models: mean-squared-error } \\
\hline Eco-Flex 00-30 & $1.41 \times 10^{-5}$ & $2.34 \times 10^{-6}$ & $3.14 \times 10^{-6}$ & $9.47 \times 10^{-6}$ & $2.25 \times 10^{-5}$ \\
\hline Eco-Flex 00-50 & $6.89 \times 10^{-5}$ & $1.22 \times 10^{-6}$ & $2.06 \times 10^{-6}$ & $4.33 \times 10^{-5}$ & $8.96 \times 10^{-5}$ \\
\hline Dragonskin & $3.74 \times 10^{-4}$ & $7.43 \times 10^{-5}$ & $4.63 \times 10^{-5}$ & $2.00 \times 10^{-4}$ & $6.53 \times 10^{-3}$ \\
\hline TangoBlackPlus & $1.60 \times 10^{-5}$ & $6.21 \times 10^{-5}$ & $5.68 \times 10^{-5}$ & $4.31 \times 10^{-5}$ & $3.87 \times 10^{-5}$ \\
\hline \multicolumn{6}{|c|}{ Constitutive models: $p$-value } \\
\hline Eco-Flex 00-30 & 0.0396 & 0.6534 & 0.2605 & 0.1608 & 0.0013 \\
\hline Eco-Flex 00-50 & 0.3469 & 0.7586 & 0.5021 & 0.6337 & 0.1834 \\
\hline Dragonskin & 0.3439 & 0.7831 & 0.9440 & 0.4067 & $2.48 \times 10^{-7}$ \\
\hline TangoBlackPlus & 0.4917 & 0.3982 & 0.3749 & 0.4485 & 0.9778 \\
\hline
\end{tabular}

Note: For each hyperelastic model, the behavior predicted by the model was compared to the real one using a paired $t$-test. The shaded cells show close agreement between the compared curves and, thus, are representative of that specific material. 


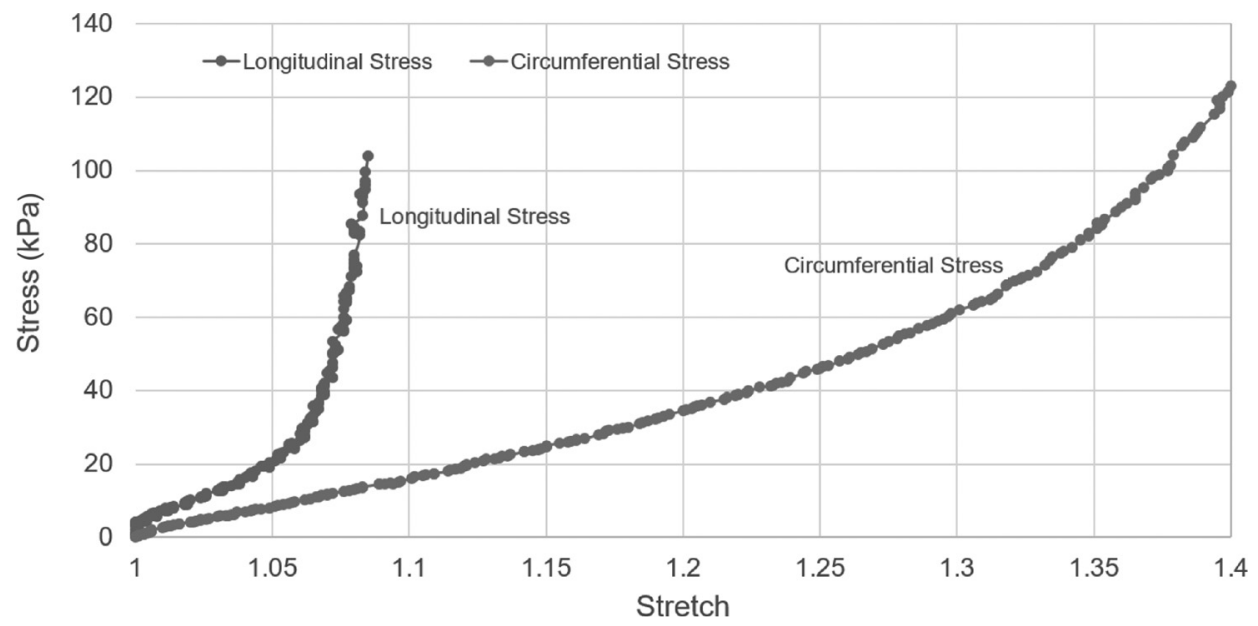

Fig. 5 Stress-stretch behavior of the thoracic aorta as found in Ref. [35]

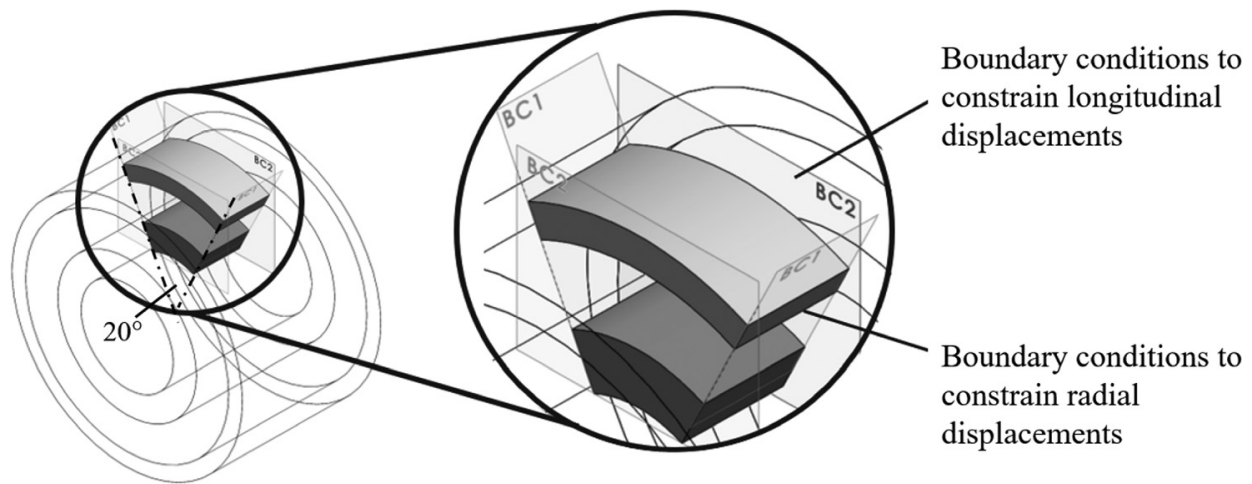

Fig. 6 Axial-symmetric modeling of the vessel (outer gray section) for numerical simulations. Two boundary conditions were applied which constrain longitudinal and radial displacements. Hence, the part can only move sliding along the BC1/BC2 planes.

box via a hose. Hence, the compliance of the phantom can be tuned adjusting the water-air ratio of the compliance chamber. A throttle valve was added to the outlet of phantom to mimic the systemic flow resistance of small vessels.

2.6 Validation Protocols. The mechanical properties of this aortic phantom were analyzed through two sets of experiments, aiming at characterizing both nonpulsatile (inspired by Biglino et al. [26]) and pulsatile conditions (derived from the standard protocol ISO 5840-3:2013).

2.6.1 Static Validation. The nonpulsatile analysis focused on the distensibility of the phantom. A motorized syringe pump was connected to the phantom (Fig. 12). A pressure sensor at the outlet of the phantom monitored the internal phantom pressure.

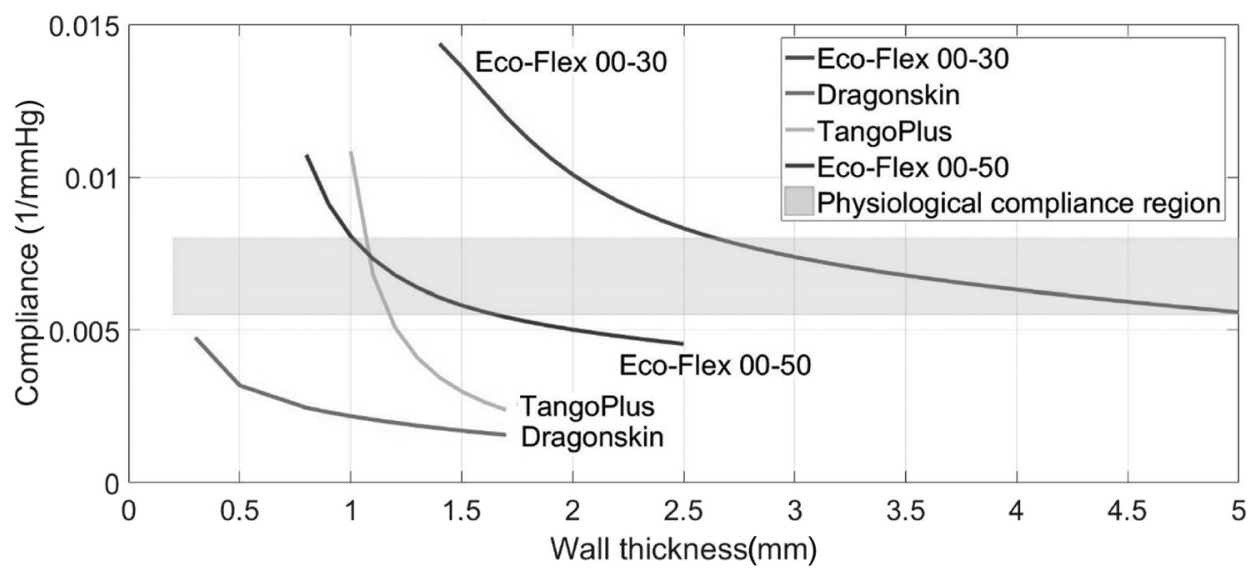

Fig. 7 Compliance values of TangoBlackPlus FLX 980 (Stratasys, Inc.), Eco-Flex 00-30, EcoFlex 00-50, and Dragon Skin 30 (smooth-on) varying the thickness of the hollow tube model (see Fig. 6). Except from Dragonskin, the materials achieve a distensibility value which is within the physiological range (see shaded area) [36]. 


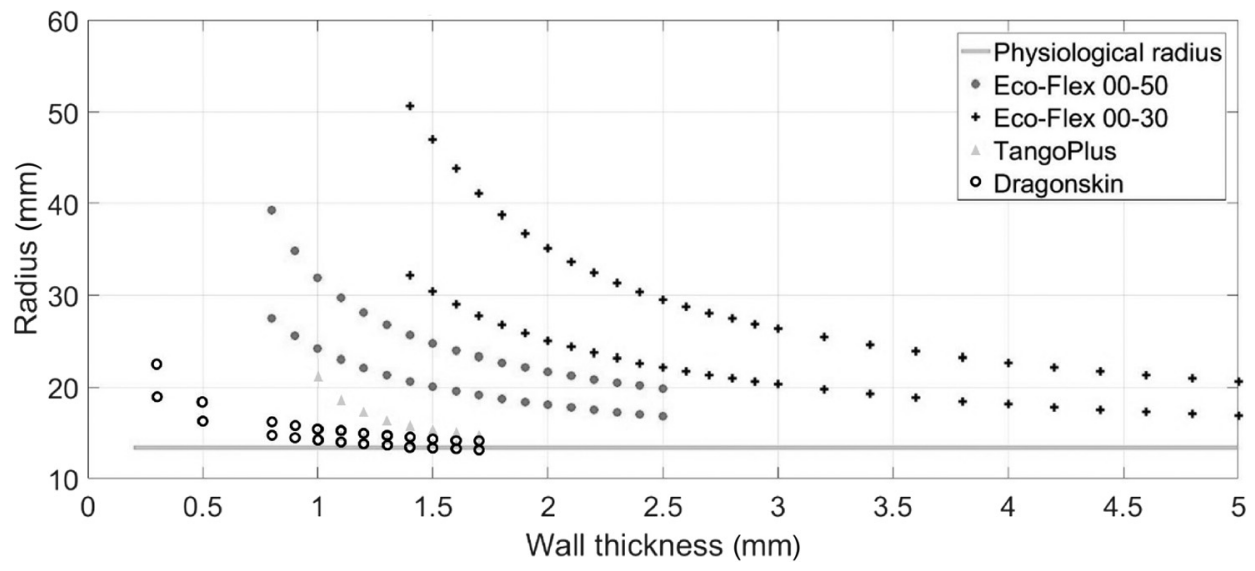

Fig. 8 Wall thickness versus radius for all explored materials. Each material was tested at $80 \mathrm{mmHg}$ (lower curve) and $120 \mathrm{mmHg}$ (upper curve). The gray line at the bottom of the graph shows the physiological reference radius that was obtained by the CT scan.

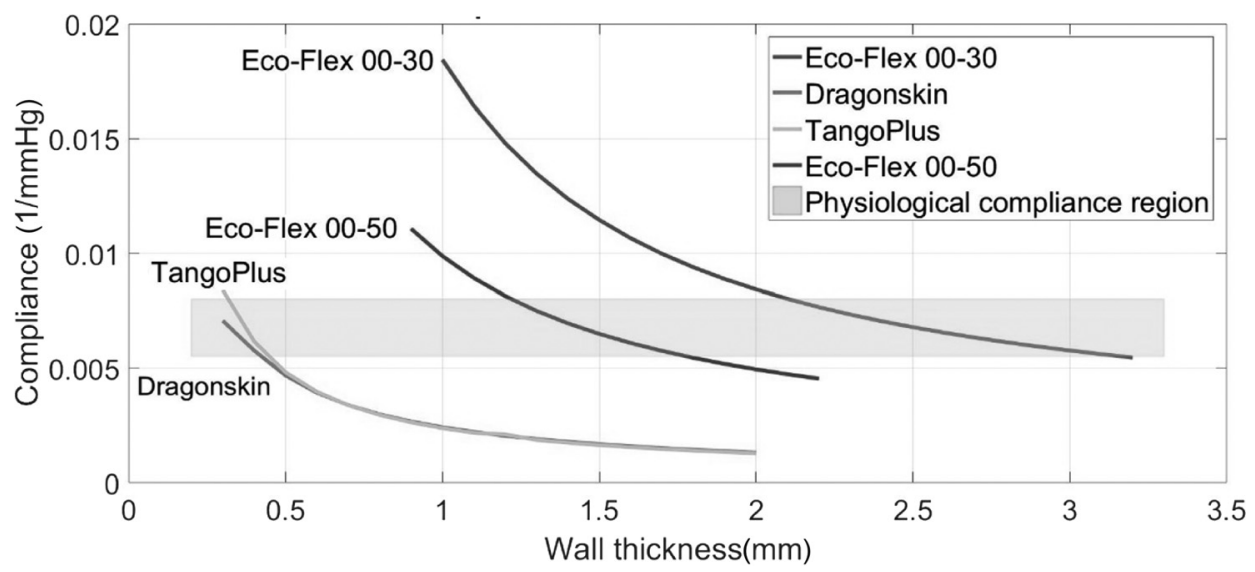

Fig. 9 Wall thickness versus compliance values for the four materials varying the thickness of the hollow tube model. All distensibility curves intersect with the reference interval of the physiological values according to Ref. [36].

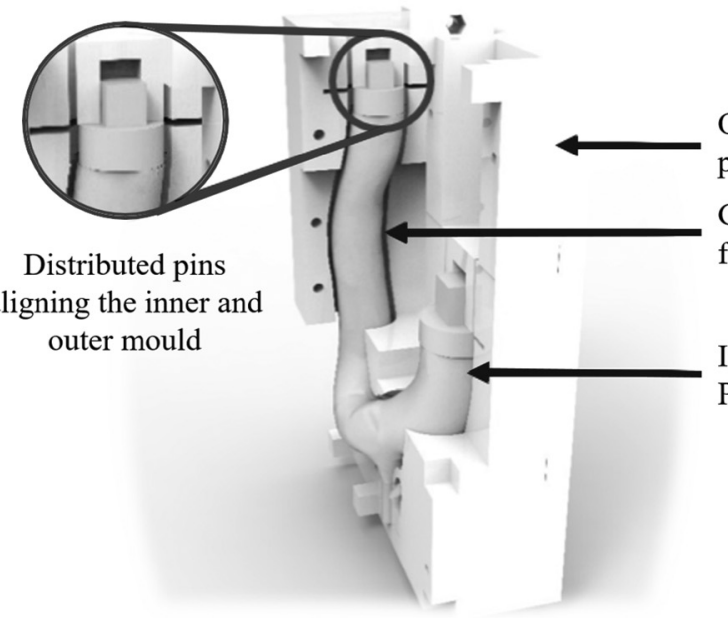

Outer rigid mould made of several 3D printed Nylon voxels

Gap between the inner and outer mould filled with silicone material

Inner core made of

Poly Vinyl Alcohol (PVA)

Fig. 10 Three-dimensional CAD model of the mold used to fabricate the flexible phantom aorta. The inner core is made of PVA, a dissoluble material. The outer mold is made of Nylon and divided into voxels to allow the extraction of the silicone phantom after curing. The inner mold is aligned with the outer one using distributed pins. 


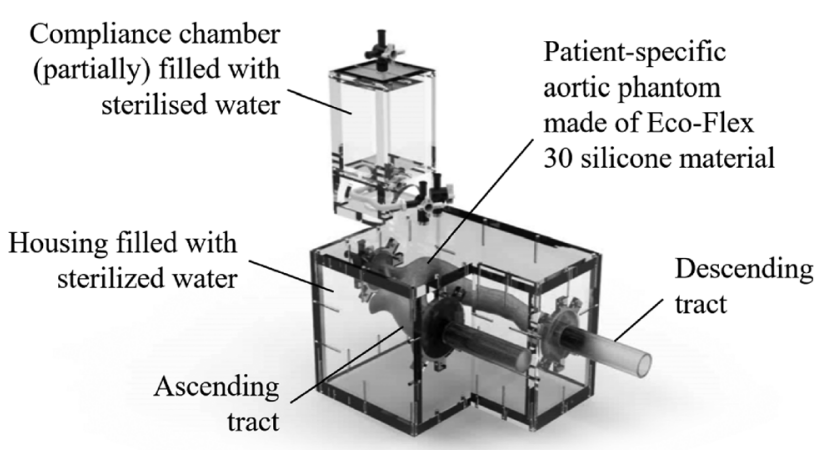

Fig. 11 Overall setup of the developed phantom. The vesse (gray) was manufactured using a casting procedure and then placed into an acrylic water-tight housing connected to a compliance chamber. The water surrounding the phantom in the housing ensures the physiological orientation. The level of water inside the compliance chamber can be adjusted using the luer lock valve. The two chambers are connected via a $10 \mathrm{~mm}-$ diameter rigid tube.

Hence, the data of volume change and pressure inside the phantom were collected and analyzed. On the one hand, the phantom was filled to reach a nondeformed condition. Then, the syringe was squeezed until a pressure of $120 \mathrm{mmHg}$ was reached. During the inflation process, the volume and pressure change were recorded for the diastolic and systolic conditions. This procedure was repeated for various compliance configurations by changing the water level in the Windkessel compliance chamber in the nondeformed condition.

The compliance of the aortic phantom was computed for different water levels using the following equation:

$$
C=\frac{\frac{\Delta V}{V}}{\Delta P}\left(\mathrm{mmHg}^{-1}\right)
$$

$\Delta V$ is the difference between the systolic and diastolic volume, $V$ is the diastolic volume, and $\Delta P$ is the difference between systolic $(120 \mathrm{mmHg})$ and diastolic $(80 \mathrm{mmHg})$ pressure monitored by the pressure sensor.

2.6.2 Pulsatile Validation. To investigate the behavior of the phantom under pulsatile conditions, the phantom was connected to a commercially available ViVitro pulse duplicator, simulating the function of the heart by generating pulsatile flow. The experiments were setup so that the pump ejected water under pressure through the aortic valve inlet of the mock aorta, delivering the flow exiting from the descending portion of the aorta to the atrium, passing through the lumped after-load. This experimental setup allows to investigate the distensibility of the aortic phantom as well as the effect of the systemic resistance on the pressure (controlled by the throttle valve) inside the phantom. Under pulsatile flow, the vessel deformation was recorded by a high frame ratio camera placed above the phantom. After calibrating the camera's intrinsic and extrinsic parameters, a segmentation algorithm was implemented using the image processing MATLAB toolbox. First, a RoI was manually selected showing a section of the aorta. Then, a priori knowledge is given to the algorithm about the background of the images. Hence, the aorta could be segmented from the series of images using thresholding resulting in the assessment of the phantom's compliance. The pressure inside the phantom was recorded using a catheter tip pressure transducer interfaced with the system. This experimental procedure was conducted for various compliance configurations of the Windkessel chamber by changing the water/air ratio in the compliance chamber. The experiments were repeated for mean pressures of 80,100 , and $120 \mathrm{mmHg}$.

2.6.3 Magnetic Resonance Imaging Compatibility Test. An MR scan was carried out on the phantom adopting a threedimensional fluid attenuated inversion recovery. This sequence allows to strongly reduce the signal arising from the silicone, resulting in a better contrast on the wall of the phantom thanks to the surrounding water. The phantom was scanned twice: in deflated $(0 \mathrm{mmHg})$ and inflated $(120 \mathrm{mmHg})$ conditions.

\section{Results and Discussion}

3.1 Nonpulsatile Test. The results of the nonpulsatile tests are summarized in Table 3. The compliance values of the phantom are determined for a series of water level inside the Windkessel compliance chamber. With an increasing water/air ratio, the compliance of the phantom decreases. The low values of standard deviation demonstrate the repeatability and accurate control in the compliance values of the aortic phantom. This analysis quantifies the distensibility of the aortic section at the aortic arch under

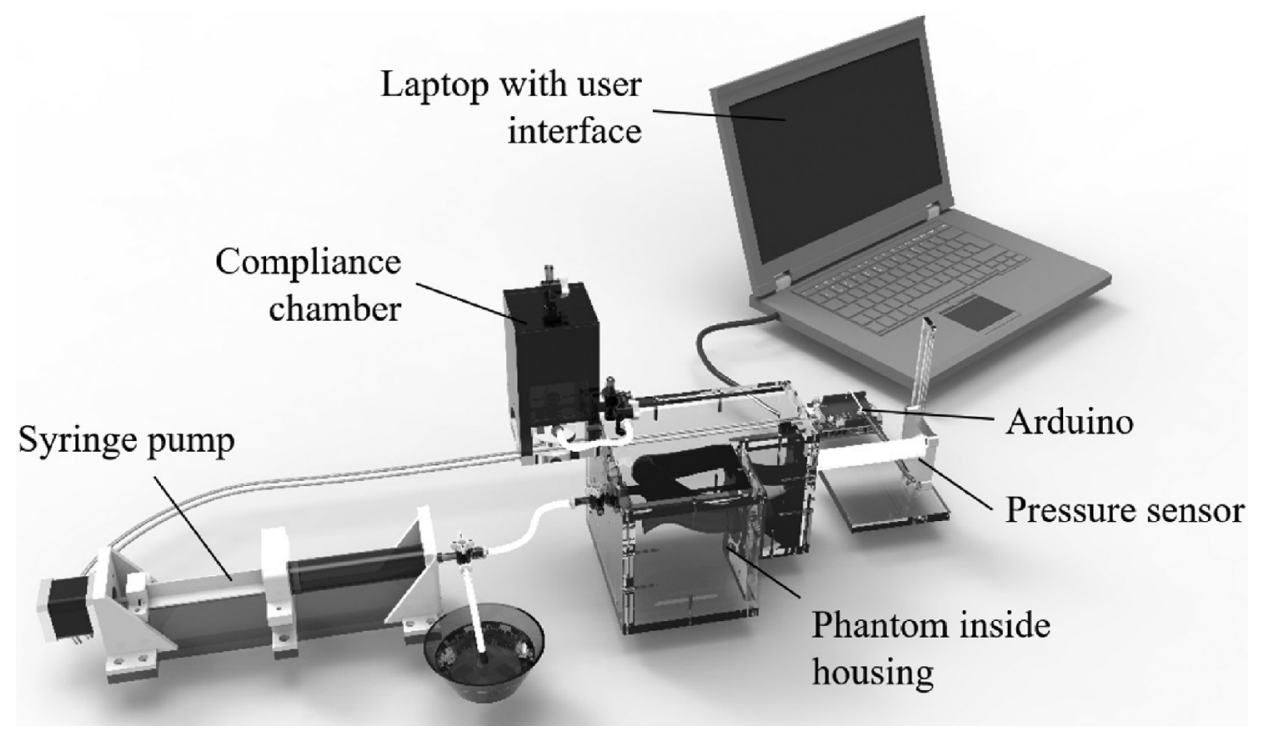

Fig. 12 Static validation setup. The phantom is placed inside the housing and filled up with water. The inlet of the vessel is closed. The outlet of the phantom is connected to a pressure sensor. The aortic branch is actuated using a syringe pump. The system is controlled via a user interface and an Arduino board. 
Table 3 Results of the nonpulsatile test

\begin{tabular}{|c|c|c|c|c|c|c|c|c|c|}
\hline Water level inside Windkessel (mm) & 10 & 20 & 30 & 40 & 50 & 60 & 70 & 80 & 90 \\
\hline Compliance $\left(\mathrm{mmHg}^{-1} 10^{-3}\right)$ & 2.14 & 1.96 & 1.82 & 1.70 & 1.56 & 1.43 & 1.27 & 1.13 & 1.07 \\
\hline Standard deviations $\left(10^{-5} \mathrm{mmHg}\right)$ & 1.94 & 0.46 & 2.09 & 1.83 & 1.47 & 1.38 & 0.55 & 1.18 & 0.73 \\
\hline
\end{tabular}

Note: For each water level in the compliance chamber, the distensibility value of the aortic phantom is determined.

Table 4 Results of the pulsatile tests

\begin{tabular}{|c|c|c|c|c|c|}
\hline Configuration $(\mathrm{mm} \mathrm{Hg})$ & Standard deviations $(\mathrm{mmHg})$ & $P_{\min }$ & $P_{\text {mean }}$ & $P_{\max }$ & Compliance $\left(\mathrm{mmHg}^{-1} 10^{-3}\right)$ \\
\hline $100 \%$ water, 120 & 0.38 & 89.61 & 125.23 & 184.34 & 0.79 \\
\hline $100 \%$ water, 100 & 0.44 & 64.94 & 103.22 & 165.42 & 0.83 \\
\hline $100 \%$ water, 80 & 0.72 & 44.54 & 83.61 & 146.11 & 1.00 \\
\hline $50 \%$ water, 120 & 0.66 & 97.35 & 121.40 & 152.63 & 1.56 \\
\hline $50 \%$ water, 100 & 0.28 & 75.69 & 102.33 & 134.96 & 1.45 \\
\hline $50 \%$ water, 80 & 0.34 & 52.27 & 83.30 & 119.00 & 1.58 \\
\hline $0 \%$ water, 120 & 1.03 & 106.43 & 124.71 & 150.98 & 1.77 \\
\hline $0 \%$ water, 100 & 0.23 & 81.01 & 100.40 & 127.10 & 2.04 \\
\hline $0 \%$ water, 80 & 0.25 & 58.97 & 79.97 & 108.62 & 2.06 \\
\hline
\end{tabular}

Note: For a number of water levels inside the Windkessel chamber and mean pressures of 80,100 , and $120 \mathrm{mmHg}$, pressure values and the compliance of the aortic phantom vessel using visual tracking are determined.

various constraints with regards to the pressure inside the phantom and the Windkessel compliance configuration. The range of resulting distensibility values in Table 3 are in fact in close agreement with the physiological values. In particular, considering the wall thickness of the model presented in this work $(2 \mathrm{~mm})$, and the standard deviation, the distensibility found fits in the range 1.9-3.7 $10^{-3} \mathrm{mmHg}^{-1}$ reported by Baeck et al. [32].

3.2 Pulsatile Test. For a number of water levels inside the Windkessel compliance chamber and pressures inside the phantom, a pressure waveform and a diameter variation of ten cardiac cycles were analyzed. Parameters such as the minimum, maximum, and mean pressures, compliance of aortic phantom as well as standard deviation were computed as shown in Table 4 .

Figures 13 and 14 show aortic pressure waveforms for a constant Windkessel compliance and a constant mean pressure inside the phantom of $100 \mathrm{mmHg}$, respectively. In Fig. 13, three aortic pressure waveforms for three different configurations three curves representing 80,100 , and $120 \mathrm{mmHg}$ are shown. These configurations have the same compliance value and different mean pressure as result of a change in the lumped resistance module. The curves appear very similar in shape, with a constant offset. In Fig. 14, on the other hand, three waveforms with the same mean pressure of $100 \mathrm{mmHg}$ and different compliance values (i.e., different water/ air ratios inside the Windkessel chamber) are depicted. In this case, the pulse pressure changes according to the level of distensibility achievable by the phantom.

This pulsatile analysis investigates the behavior of the phantom under dynamic conditions. As it can be seen in Fig. 13, the pressure rises with a semirigid shift for a fixed compliance value as the systemic resistance increases. For the same mean pressure value, the compliance of the system affects the aortic pulse pressure rising for low level of compliance and decreasing for high values of compliance. This behavior is evident in real physiological conditions, where the lack of compliance of the arteries, due to stiffening of their wall leads to a higher $\Delta P$ and an increased systemic resistance, resulting in an overall state of hypertension $[38,39]$. The pressure curve both in systole and in diastole follows the physiological trend. Moreover, the phantom is able to mimic the dicrotic notch that occurs after the systole [40]

However, an undesired behavior is shown for high values of compliance-another peak appears after the notch (see Fig. 14, $0 \%$ water). This behavior could be due to the fact that the

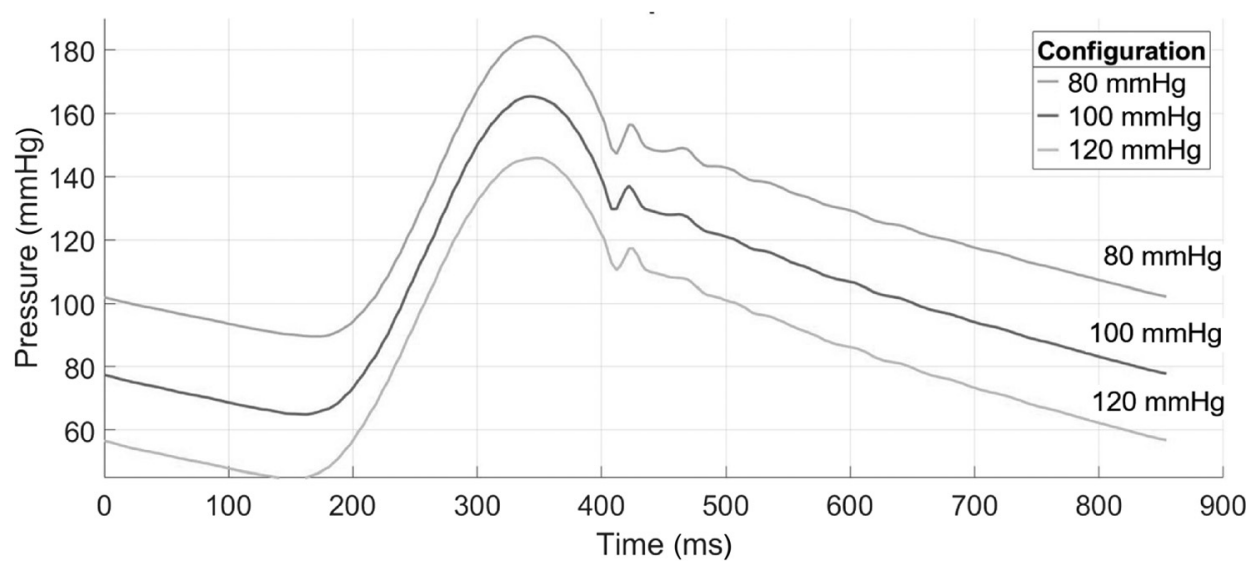

Fig. 13 Pressure curve of the aortic phantom: The compliance chamber is filled with water. The aortic pressure waveform change is due to an increase in the lumped systemic resistance by acting on the throttle valve. The three curves represent 80,100 , and $120 \mathrm{mmHg}$. 


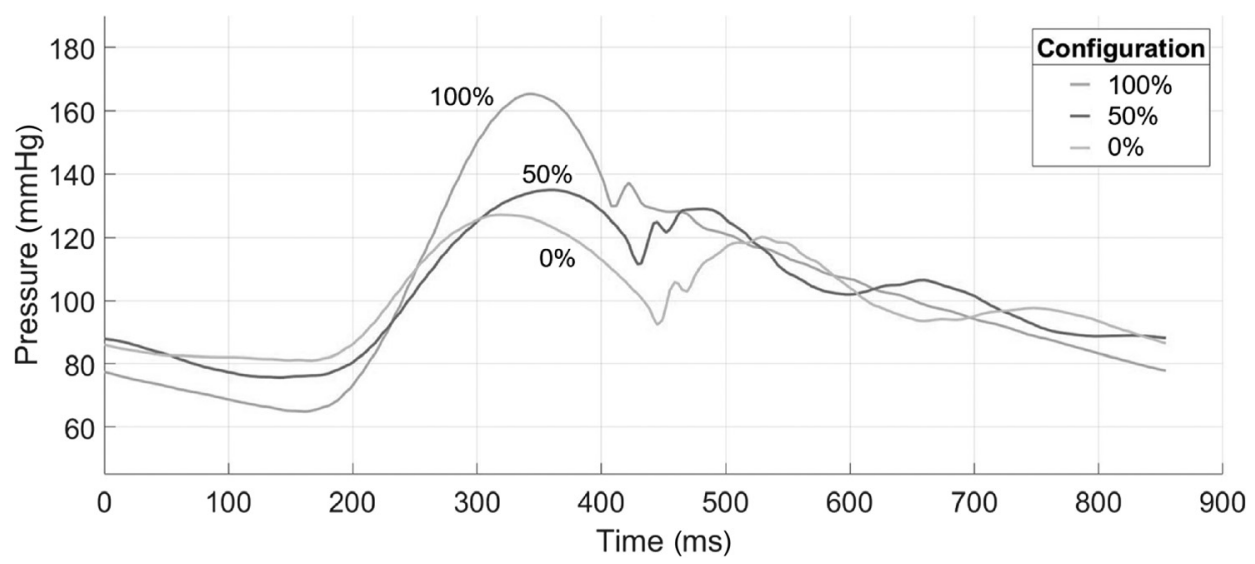

Fig. 14 Pressure curve of the aortic phantom at $100 \mathrm{mmHg}$ : The Windkessel compliance chamber is filled with $100 \%, 50 \%$, and $0 \%$ water

phantom undergoes a rise in pressure during the diastole due to the movement of a certain amount of water from the housing to the Windkessel compliance chamber that takes few millisecond to drop back in the phantom housing. The presence of this peak impairs the achievement of a perfect physiological behavior of the pressure curve.

3.3 Magnetic Resonance Compatibility Test. In Fig. 15, the result of the MR scan is shown proving two descriptive views of the reconstructed volume. On the left, the top view of the phantom in its deflated and inflated state is given. On the right-hand side, the cross-sectional view of both conditions is depicted.

The third and last validation protocols support the MR compatibility claim with practical results. From Fig. 15, two conclusions can be inferred: The manufacturing process was sufficiently precise as the overall thickness of the phantom is reasonably uniform. The second observation concerns its behavior when inflated: the deformation of the vessel occurs toward the exterior of the housing. This behavior is in agreement with the asymmetric distension observed in vivo with MRI scans on healthy volunteers reported by Van Prehn et al. [41].

\section{Conclusions}

In this paper, we describe a tunable compliant vascular phantom that was designed, created and validated with a novel approach based on FEA. The obtained phantom performance was assessed in static and dynamic behavior with respect to clinically relevant mechanical properties. The phantom shows values of

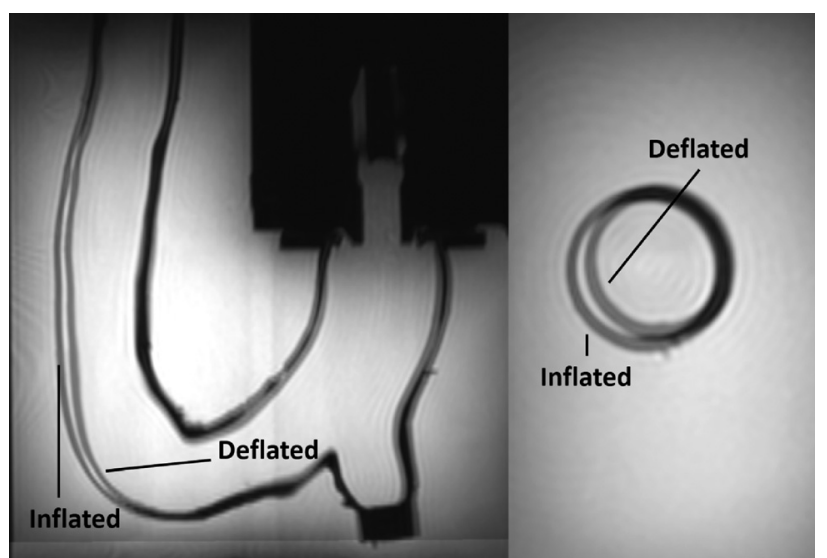

Fig. 15 Overlapping of two scans of the same phantom at 0 and $120 \mathrm{mmHg}$ pressure compliance in the physiological range. Both, the pressure curves and the asymmetrical behavior of the expansion are in agreement with the literature. To the best of our knowledge, this is the first description of a novel design of a vascular phantom with the tunable compliance. The described methodology offers a frame of reference for developing mock circulatory systems in healthy and pathologic conditions, which have high potential to be used in a broad range of environments.

\section{Acknowledgment}

The authors thank Dr. M. Sokolska from Macmillan Cancer Centre (London, UK) who has kindly helped the MR acquisition procedure.

The study was reviewed and approved by the internal review board of the research group, which was the relevant crossinstitutional committee responsible for assessing the methodological appropriateness and ethicality of the study design (AO San Camillo-Forlanini, Rome, Italy). All subjects gave written informed consent in accordance with the Declaration of Helsinki. Further approval by the Ethics Committee was not required, since the research involved anonymized records and datasets that exist in the public domain, where appropriate permissions had already been obtained and it is not possible to identify individuals from the information provided.

\section{Funding Data}

- The Engineering and Physical Sciences Research Council (Grant Nos. EP/N509577/1 and EP/S014039/1).

- The Springboard Award of the Academy of Medical Sciences (Grant No. SBF003\1109).

\section{Appendix}

A brief explanation of the formulation of the hyperelastic models used and their strain energy functions $U$ is given in Eqs. (A1)-(A3) [42]

$$
\operatorname{Ogden} U \stackrel{\text { def }}{=} \sum_{\mathrm{i}=1}^{\mathrm{N}} \frac{2 \mu_{i}}{\alpha_{i}^{2}}\left(\lambda_{1}^{\alpha_{i}}+\lambda_{2}^{\alpha_{i}}+\lambda_{3}^{\alpha_{i}}-3\right)+\sum_{i=1}^{N} \frac{1}{D_{i}}\left(J_{\mathrm{el}}-1\right)^{2 i}
$$

Ogden strain energy potential is expressed in terms of the principal stretches. The order $N$ of the strain energy function has been considered up to the third-order. For each order, $\alpha_{i}, \mu_{i}$, and $D_{i}$ values have been directly computed by the software. $\lambda_{i}$ are the principal stretches 
Reduced Polynomial $U \stackrel{\text { def }}{=} \sum_{i=1}^{N} C_{i 0}\left(\bar{I}_{1}-3\right)^{i}+\sum_{i=1}^{N} \frac{1}{D_{i}}\left(J_{\mathrm{el}}-1\right)^{2 i}$

This is a particular form of the polynomial model where, also in this case, $C_{i 0}$ and $D_{i}$ are temperature-dependent material parameters computed directly by the software. If the order $N$ is equal to 1 , the Neo-Hookean form is obtained

$$
\text { Neo }- \text { Hookean } U \stackrel{\text { def }}{=} C_{10}\left(\bar{I}_{1}-3\right)+\frac{1}{D_{1}}\left(J_{\text {el }}-1\right)^{2}
$$

In all these formulation, $\overline{I_{1}}$ is the first deviatoric strain, $J_{\mathrm{el}}$ is the elastic volume ratio.

\section{References}

[1] Mozaffarian, D., Benjamin, E. J., Go, A. S., Arnett, D. K., Blaha, M. J., Cushman, M., Das, S. R., de Ferranti, S., Després, J.-P., Fullerton, H. J., Howard, V. J., Huffman, M. D., Isasi, C. R., Jiménez, M. C., Judd, S. E., Kissela, B. M., Lichtman, J. H., Lisabeth, L. D., Liu, S., Mackey, R. H., Magid, D. J., McGuire, D. K., Mohler, E. R., III, Moy, C. S., Muntner, P., Mussolino, M. E., Nasir, K., Neumar, R. W., Nichol, G., Palaniappan, L., Pandey, D. K., Reeves, M. J., Rodriguez, C. J., Rosamond, W., Sorlie, P. D., Stein, J., Towfighi, A., Turan, T. N., Virani, S. S., Woo, D., Yeh, R. W., and Turner, M. B., 2016, "Heart Disease and Stroke Statistics-2016 Update a Report From the," Am. Heart Assoc. Circulation., 133(4), pp. e38-e48.

[2] Wilkins, E., Wilson, L., Wickramasinghe, K., Bhatnagar, P., Leal, J., LuengoFernandez, R., Burns, R., Rayner, M., and Townsend, N., 2017, "European Cardiovascular Disease Statistics 2017," European Heart Network, Brussels, Belgium.

[3] OECD, 2015, “Life Expectancy at Birth,” Health at a Glance 2015, Vol. 2013, OECD Publishing, Paris, France.

[4] Knight, A., 2011, "Weighing the Costs and Benefits of Animal Experiments," Eighth World Congress Alternatives to Animal Experimentation, Montreal, Canada, Aug. 21-25, pp. 289-294.

[5] P. Puska, B. Norrving, and Mendis, S., Eds., 2011, Global Atlas on Cardiovascular Disease Prevention and Control, World Health Organization/ World Heart Federation/World Stroke Organization, Geneva, Switzerland.

[6] Gatehouse, P. D., Keegan, J., Crowe, L. A., Masood, S., Mohiaddin, R. H., Kreitner, K. F., and Firmin, D. N., 2005, "Applications of Phase-Contrast Flow and Velocity Imaging in Cardiovascular MRI," Eur. Radiol., 15(10), pp. 2172-2184.

[7] Hoi, Y., Woodward, S. H., Kim, M., Taulbee, D. B., and Meng, H., 2006, "Validation of CFD Simulations of Cerebral Aneurysms With Implication of Geometric Variations," ASME J. Biomech. Eng., 128(6), pp. 844-851.

[8] Morris, P. D., Narracott, A., von Tengg-Kobligk, H., Soto, D. A. S., Hsiao, S., Lungu, A., Evans, P., Bressloff, N. W., Lawford, P. W., Rodney Hose, D., and Gunn, J. P., 2016, "Computational Fluid Dynamics Modelling in Cardiovascular Medicine," Heart, 102(1), pp. 18-28.

[9] Taylor, C. A., and Figueroa, C. A., 2009, "Patient-Specific Modelling of Cardiovascular Mechanics," Annu. Rev. Biomed. Eng., 11(1), pp. 109-134.

[10] Kung, E. O., Les, A. S., Figueroa, C. A., Medina, F., Arcaute, K., Wicker, R. B., McConnell, M. V., and Taylor, C. A., 2011, "In Vitro Validation of Finite Element Analysis of Blood Flow in Deformable Models," Ann. Biomed. Eng., 39(7), pp. 1947-1960.

[11] Hessenthaler, A., Gaddum, N. R., Holub, O., Sinkus, R., Röhrle, O, and Nordsletten, D., 2017, "Experiment for Validation of Fluid-Structure Interaction Models and Algorithms," Int. J. Numer. Methods Biomed. Eng., 33(9), p. e2848.

[12] Leon, M. B., Smith, C. R., Mack, M., Miller, D. C., Moses, J. W., Svensson, L. G., Tuzcu, E. M., Webb, J. G., Fontana, G. P., Makkar, R. R., Brown, D. L., Block, P. C., Guyton, R. A., Pichard, A. D., Bavaria, J. E., Herrmann, H. C., Douglas, P. S., Petersen, J. L., Akin, J. J., Anderson, W. N., Wang, D., and Pocock, S., 2010, "Transcatheter Aortic-Valve Implantation for Aortic Stenosis in Patients Who Cannot Undergo Surgery," New Engl. J. Med., 363(17), pp. 1597-1607.

[13] Palombi, A., Bosi, G. M., Di Giuseppe, S., De Momi, E., Homer-Vanniasinkam, S., Burriesci, G., and Wurdemann, H. A., 2019, "Sizing the Aortic Annulus With a Robotised, Commercially Available Soft Balloon Catheter: In Vitro Study on Idealised Phantoms," IEEE International Conference on Robotics and Automation, Montreal, Canada, pp. 6230-6236.

[14] Serruys, P. W., De Jaegere, P., Kiemeneij, F., Macaya, C., Rutsch, W., Heyndrickx, G., Emanuelsson, H. U., Marco, J., Legrand, V. M. G., Materne, P. H., Belardi, J. A., Sigwart, U., Colombo, A., Goy, J.-J., van den Heuvel, P., Delcan, J., Morel, M.-A. M., and Belardi, J., 1994, "A Comparison of BalloonExpandable-Stent Implantation With Balloon Angioplasty in Patients With Coronary Artery Disease," New Engl. J. Med., 331(8), pp. 489-495.

[15] Pasta, S., Scardulla, F., Rinaudo, A., Raffa, G. M., D'ancona, G., Pilato, M. and Scardulla, C., 2016, "An In Vitro Phantom Study on the Role of the BirdBeak Configuration in Endograft Infolding in the Aortic Arch," J. Endovascular Ther., 23(1), pp. 172-181.
[16] Murai, E. H., Homer-Vanniasinkam, S., Silveira, P. G., Dai, J. S., Martins, D. and Wurdemann, H. A., 2018, "Towards a Modular Suturing Catheter for Minimally Invasive Vascular Surgery," IEEE International Conference on Robotics and Automation, Brisbane, Australia, May 21-25, pp. 44-49.

[17] Neragi-Miandoab, S., and Michler, R. E., 2013, "A Review of Most Relevant Complications of Transcatheter Aortic Valve Implantation," ISRN Cardiol., 2013, pp. 1-12.

[18] van Gameren, M., Witsenburg, M., Takkenberg, J. J. M., Boshoff, D., Mertens, L., van Oort, A. M., de Wolf, D., Freund, M., Sreeram, N., Bokenkamp, R., Talsma, M. D., and Gewillig, M., 2006, "Early Complications of Stenting in Patients With Congenital Heart Disease: A Multicentre Study," Eur. Heart J. 27(22), pp. 2709-2715.

[19] Russ, C., Gessat, M., Szekely, G., and Falk, V., 2012, "Rapid Prototyping of Silicone-Based Phantom Models for Stent Simulation Validation," MICCAIStent, Nice, France, Oct. 1, pp. 80-87.

[20] Biglino, G., Cosentino, D., Steeden, J. A., De Nova, L., Castelli, M., Ntsinjana, H., Pennati, G., Taylor, A. M., and Schievano, S., 2015, "Using 4D Cardiovascular Magnetic Resonance Imaging to Validate Computational Fluid Dynamics: A Case Study," Front. Pediatr., 3(107), pp. 1-10.

[21] Vismara, R., Pavesi, A., Votta, E., Taramasso, M., Maisano, F and Fiore, G. B., 2011, "A Pulsatile Simulator for the In Vitro Analysis of the Mitral Valve With Tri-Axial Papillary Muscle Displacement," Int. J. Artif. Organs, 34(4), pp. 383-391.

[22] Meess, K. M., Izzo, R. L., Dryjski, M. L., Curl, R. E., Harris, L. M., Springer, M., Siddiqui, A. H., Rudin, S., and Ionita, C. N., 2017, "3D Printed Abdominal Aortic Aneurysm Phantom for Image Guided Surgical Planning With a Patient Specific Fenestrated Endovascular Graft System," International Society for Optics \& Photonics Conference Proceedings, San Francisco, CA, Feb. 11, p. $101380 \mathrm{P}$.

[23] Penza, V., Ciullo, A. S., Moccia, S., Mattos, L. S., and De Momi, E., 2018 , "EndoAbS Dataset: Endoscopic Abdominal Stereo Image Dataset for Benchmarking 3D Stereo Reconstruction Algorithms," Int. J. Med. Rob. Comput. Assisted Surg., 14(5), p. e1926.

[24] Ahamed, T., Peattie, R. A., Dorfmann, L., and Cherry Kemmerling, E. M., 2018, "Pulsatile Flow Measurements and Wall Stress Distribution in a Patient Specific Abdominal Aortic Aneurysm Phantom," ZAMM J. Appl. Math. Mech. 98(12), pp. 2258-2274

[25] Yazdi, S. G., Geoghegan, P. H., Docherty, P. D., Jermy, M., and Khanafer, A., 2018, "A Review of Arterial Phantom Fabrication Methods for Flow Measurement Using PIV Techniques," Ann. Biomed. Eng., 46(11), pp. 1697-1721.

[26] Biglino, G., Verschueren, P., Zegels, R., Taylor, A. M., and Schievano, S., 2013, "Rapid Prototyping Compliant Arterial Phantoms for In-Vitro Studies and Device Testing," J. Cardiovasc. Magn. Reson., 15(1), p. 2.

[27] Wang, Y., Joannic, D., Juillion, P., Monnet, A., Delassus, P., Lalande, A., and Fontaine, J. F., 2018, "Validation of the Strain Assessment of a Phantom of Abdominal Aortic Aneurysm: Comparison of Results Obtained From Magnetic Resonance Imaging and Stereovision Measurements," ASME J. Biomech. Eng. 140(3), p. 031001 .

[28] Arcaute, K., and Wicker, R. B., 2008, "Patient-Specific Compliant Vessel Manufacturing Using Dip-Spin Coating of Rapid Prototyped Moulds," ASME J. Manuf. Sci. Eng., 130(5), p. 051008.

[29] Kvasnytsia, M., Famaey, N., Böhm, M., and Verhoelst, E., 2016, "Patient Specific Vascular Benchtop Models for Development and Validation of Medical Devices for Minimally Invasive Procedures," J. Med. Rob. Res., 1(3), p. 1640008.

[30] Fedorov, A., Beichel, R., Kalpathy-Cramer, J., Finet, J., Fillion-Robin, J.-C., Pujol, S., Bauer, C., Jennings, D., Fennessy, F., Sonka, M., Buatti, J., Aylward, S. R., Miller, J. V., Pieper, S., and Kikinis, R., 2012, "3D Slicer as an Image Computing Platform for the Quantitative Imaging Network," Magn. Reson. Imaging, 30(9), pp. 1323-1341.

[31] Wang, K., Zhao, Y., Chang, Y.-H., Qian, Z., Zhang, C., Wang, B., Vannan, M A., and Wang, M.-J., 2016, "Controlling the Mechanical Behavior of DualMaterial 3D Printed Meta-Materials for Patient-Specific Tissue-Mimicking Phantoms," Mater. Des., 90, pp. 704-712.

[32] Baeck, K., Lopes, P., Verschueren, P., Biglino, G., and Capelli, C., 2013, "State of the Art in 3D Printing of Compliant Cardiovascular Models: HeartPrint Material Characterization of HeartPrint Models and Comparison With Arterial Tissue Properties," Workshop on New Technologies for Computer/Robot Assisted Surgery, Verona, Italy, Sept. 11-13, pp. 1-4.

[33] Vismara, R., Laganà, K., Migliavacca, F., Schievano, S., Coats, L., Taylor, A., and Bonhoeffer, P., 2009, "Experimental Setup to Evaluate the Performance of Percutaneous Pulmonary Valved Stent in Different Outflow Tract Morphologies," Artif. Organs, 33(1), pp. 46-53.

[34] Baeck, K., Lopes, P., and Verschueren, P., 2014, "Material Characterization of HeartPrint ${ }^{(B)}$ Models and Comparison With Arterial Tissue Properties," Materialise, Leuven, Belgium.

[35] BS, 2015, "Rubber, Vulcanized or Thermoplastic-Determination of the Effect of Liquids," British Standards Institution, London, UK, Standard No. BS ISO 1817.

[36] Kamenskiy, A. V., Dzenis, Y. A., Kazmi, S. A., Pemberton, M. A., Pipinos, I. I., Phillips, N. Y., Herber, K. Woodford, T, Bowen, R. E., Lom neth, C. S., and MacTaggart, J. N., 2014, "Biaxial Mechanical Properties of the Human Thoracic and Abdominal Aorta, Common Carotid, Subclavian, Renal and Common Iliac Arteries," Biomech. Model. Mechanobiol., 13(6), pp. 1341-1359.

[37] Ding, H., Qiao, A., Shen, L., Li, M., Chen, Z., Yu, X., and Zeng, Y., 2006, "Design of Compliance Chamber and After-Load in Apparatus for 
Cultured Endothelial Cells Subjected to Stresses," Cell Biol. Int., 30(5), pp. 439-444.

[38] Takazawa, K., Kobayashi, H., Shindo, N., Tanaka, N., and Yamashina, A., 2007, "Relationship Between Radial and Central Arterial Pulse Wave and Evaluation of Central Aortic Pressure Using the Radial Arterial Pulse Wave," Hypertens. Res., 30(3), p. 219.

[39] He, J. L., Lecarpentier, Y., Zamani, K., Coirault, C., Daccache, G., Chemla, D., Wuilliez, N., and Larsonneur, L., 1995, "Relation Between Aortic Dicrotic Notch Pressure and Mean Aortic Pressure in Adults," Am. J. Cardiol., 76(4), pp. 301-306.

[40] Nichols, W. W., Denardo, S. J., Wilkinson, I. B., McEniery, C. M., Cockcroft, J., and O'rourke, M. F., 2008, "Effects of Arterial Stiffness, Pulse Wave
Velocity, and Wave Reflections on the Central Aortic Pressure Waveform," J. Clin. Hypertens., 10(4), pp. 295-303.

[41] Van Prehn, J., Vincken, K. L., Sprinkhuizen, S. M., Viergever, M. A., Van Keulen, J. W., Van Herwaarden, J. A., Moll, F. L., and Bartels, L. W., 2009, "Aortic Pulsatile Distention in Young Healthy Volunteers Is Asymmetric: Analysis With ECG-Gated MRI," Eur. J. Vasc. Endovascular Surg., 37(2), pp. 168-174.

[42] Voges, I., Jerosch-Herold, M., Hedderich, J., Pardun, E., Hart, C., Gabbert, D. D., Hansen, J. H., Petko, C., Kramer, H. H., and Rickers, C., 2012, "Normal Values of Aortic Dimensions, Distensibility, and Pulse Wave Velocity in Children and Young Adults: A Cross-Sectional Study," J. Cardiovasc. Magn. Reson., 14(1),p. 77. 